\title{
Uncontrollable shock, forebrain norepinephrine, and stimulus selection during choice-escape learning
}

\author{
THOMAS R. MINOR \\ University of California, Los Angeles, California \\ MARY ANN PELLEYMOUNTER \\ University of North Carolina, Chapel Hill, North Carolina \\ and \\ STEVEN F. MAIER \\ University of Colorado, Boulder, Colorado
}

\begin{abstract}
Exposure to uncontrollable shock impairs later choice-escape learning in rats. A deficit occurs only when an irrelevant cue is presented on choice trials and the rat is unable to ignore the cue. Three experiments examined the role of stress-induced depletion of forebrain norepinephrine (NE) in the choice-accuracy deficit. Experiments 1 and 2 established a relationship between stressfulness of pretreatment sessions, magnitude of the deficit in later choice escape, and depletion of forebrain NE upon reexposure to a few shocks $24 \mathrm{~h}$ after pretreatment. Experiment 3 established that NE depletion is sufficient to impair choice performance. Bilateral 6-hydroxydopamine lesions of the ascending dorsal tegmental bundle mimicked the effects of inescapable shock. Lesioned rats showed a deficit in choice accuracy only when an irrelevant cue was presented during choice testing. Vehicle controls were unimpaired regardless of cue condition. These data are consistent with the notion that the ascending dorsal tegmental bundle is involved in attentionlike processing and suggest that deficits in stimulus selection following inescapable shock may result from stress-induced depletion of forebrain NE.
\end{abstract}

Although it is well established that exposure to inescapable, but not to escapable, electric shock impairs later escape performance in rats (Maier, Albin, \& Testa, 1973; Seligman, Rosellini, \& Kozak, 1975), there is still little agreement concerning the mechanism underlying this effect. Maier and Seligman (1976) argue that rats learn that their behavior and shock termination during inescapable shock are unrelated, and therefore that responding will be ineffective in producing future outcomes. This expectation of helplessness generalizes to the test task to produce cognitive, motivational, and emotional impairment. Alternatively, deficits in escape performance following inescapable shock could reflect a reduced capacity to respond. Activity deficits could arise from stress-induced depletion of brain catecholamines (Anisman, 1975; Weiss, Glazer, \& Pohorecky, 1976; Weiss, Stone, \& Harrell, 1970) or from the strengthening of competing motor patterns during inescapable shock (Bracewell \& Black, 1974; Glazer \& Weiss, 1976).

This research was supported by a grant from the University of California Senate to T. R. Minor and National Science Foundation Grant BNS 85-07451 to S. F. Maier. The authors thank N. K. Dess for helpful comments on an early draft of this manuscript. Requests for reprints should be sent to Thomas R. Minor, Department of Psychology, 405 Hilgard Ave, UCLA, Los Angeles, CA 90024-1563.
Recently, choice tasks have been used to evaluate these alternative learning and performance hypotheses (Irwin, Suissa, \& Anisman, 1980; Jackson, Alexander, \& Maier, 1980; Minor, Jackson, \& Maier, 1984; Rosellini, DeCola, \& Shapiro, 1982). The rationale is that any effect of inescapable shock on motor performance should be reflected in response speed, whereas any associative component should affect choice accuracy. Preliminary analysis of appetitively (Rosellini et al., 1982) and aversively motivated choice (Jackson et al., 1980) yielded evidence of cognitive interference. Inescapably shocked rats made more errors and required more triais to learn correct choice responses than did escapably shocked and restrained controls. Moreover, although inescapably shocked rats were slower to respond than were controls, response speed and choice accuracy were not strongly correlated on any given trial. Because persistent errors in this task represent a failure to associate specific responses with choice outcomes, such data support the idea that inescapably shocked rats have difficulty learning causal relations between their behavior and important outcomes (Maier \& Seligman, 1976).

More recent evidence, however, questions this interpretation. A detailed analysis of aversively motivated choice (Minor et al., 1984) indicated that the results of the seminal study (Jackson et al., 1980) were strongly influenced 
by two inadvertent test variables. Specifically, choiceaccuracy deficits occurred in inescapably shocked rats only when shock termination was delayed following correct responses and salient task-irrelevant cues were presented on choice trials. Choice errors resulted from an inability to ignore the irrelevant cue. Thus, while learned helplessness theory predicts that exposure to inescapable shock should interfere with the formation of response-outcome associations, the actual difficulty appeared to arise at an earlier stage of information processing, perhaps at an attentional level. This deficit in stimulus selection or filtering is not easily accommodated by the learned-helplessness hypothesis.

Overattention to irrelevant cues can be accommodated by an expanded version of the catecholamine-depletion hypothesis (Anisman, 1975; Weiss et al., 1976; Weiss et al., 1970). The attentional component of the choiceaccuracy deficit resembles the disruption of information processing that accompanies chemical lesions of the ascending dorsal tegmental bundle (ADTB). This tract arises from the pontine nucleus locus coeruleus to provide most of the noradrenergic innervation to the superior forebrain. While the exact function of the ADTB in cognition remains in question, several investigators have suggested that it plays some role in stimulus selection or filtering (Aston-Jones, 1985; Foote, Bloom, \& Aston-Jones, 1983; Gray, 1982; Mason, 1980; Segal, 1985). For instance, Mason (1980) concluded that the ADTB was involved in selective attention to relevant stimuli, and that, consequently, ADTB lesions rendered rats incapable of ceasing to pay attention to task-irrelevant stimuli.

Exposure to inescapable, but not to escapable, shock results in transient depletion of norepinephrine (NE) in the locus coeruleus and forebrain projection regions of the ADTB (Anisman \& Zacharko, 1986; Weiss et al., 1981; Weiss \& Simson, 1985). This stress-induced depletion is far smaller than that produced by chemical lesions. However, a relatively small alteration of noradrenergic transmission might be sufficient to prolong attention to task-irrelevant stimuli, especially when such cues are highly salient and correct response alternatives are masked by a delay of reinforcement.

The present study examined the contribution of NE depletion to the choice-accuracy deficit produced by prior exposure to inescapable shock. In Experiment 1, rats were exposed to different numbers of inescapable shocks during pretreatment in an attempt to influence the magnitude of the choice-accuracy deficit $24 \mathrm{~h}$ later. In Experiment 2, we sought to determine whether the level of NE depletion in projection regions of the ADTB paralleled the deficit in choice accuracy obtained in Experiment 1 under each pretreatment condition. In Experiment 3, our aim was to determine whether bilateral 6-hydroxydopamine (6-OHDA) lesions of the ADTB were sufficient to disrupt choice-escape performance in the same way that inescapable shock did.

\section{EXPERIMENT 1}

The adverse effects of inescapable shock generally increase in reliability or magnitude as the severity (intensity, duration, or number) of pretreatment shocks is increased (Anisman \& Zacharko, 1986; Looney \& Cohen, 1972; Maier, Sherman, Lewis, Terman, \& Liebeskind, 1983; Minor et al., 1984). The number of inescapable shocks received during pretreatment was varied in the first two experiments in an attempt to influence later test performance. Larger numbers of inescapable shocks were expected to result in greater impairment of later choice performance (Experiment 1) and NE depletion (Experiment 2). If stress-induced depletion of forebrain NE is responsible for the disruptive effects of irrelevant cues during choice testing in inescapably shocked rats, then the magnitude of the choice-accuracy deficit under each pretreatment condition should be closely related to the level of NE depletion at the time of testing.

In Experiment 1, rats were exposed to $0,40,80$, or 120 inescapable tailshocks in restraining tubes. Twentyfour hours later, all rats were tested for choice-escape performance in a Y-shaped maze using the procedure of Minor et al. (1984). On each trial, shock terminated when a rat chose the alley to the left of its starting position. If the right alley was chosen, an error was recorded and choice of the arm to the left of the rat's new location was required to terminate shock. An irrelevant visual cue that bore no consistent relationship to the location of the animal or to correct response alternatives was presented on each trial. Task difficulty was increased by delaying shock termination after correct responses by a variable interval.

\section{Method}

Subjects. For 1 week prior to the start of the experiment, 32 male albino rats (Charles River Co., Wilmington, MA), weighing 290-330 g, were housed in individual cages with free-access to food and water. The colony room was maintained on a 12:12-h day:night cycle. Experimental treatments occurred in the light portion of the cycle between 10:00 a.m. and 2:00 p.m.

Apparatus. Pretreatment occurred in six Plexiglas restraining tubes, $23 \mathrm{~cm}$ in length and $6 \mathrm{~cm}$ in diameter. Adjustable front walls prevented the rat from moving forward in the tube. The rat's tail extended through the rear door of the tube and was taped to a plastic rod. Unscrambled shock was delivered to electrodes attached to the rat's tail from one of four shock sources modeled after the Grason-Stadler (Series 700) shock generator. Contact was facilitated with electrode paste. Each restraining tube was housed in a dark, sound-attenuating chest.

Choice-escape testing was conducted in a symmetrical Y-shaped maze. Each of the three arms was at a $120^{\circ}$ angle with respect to the other two arms and extended from a central section that formed an equilateral triangle measuring $11 \mathrm{~cm}$ on each side. Each arm was $22.5 \times 11.0 \times 13.7 \mathrm{~cm}$. The end wall of each arm was constructed of milky Plexiglas and could be illuminated by two 6-W bulbs located directly behind the end wall. The side walls of the maze were black Plexiglas. The ceiling was clear Plexiglas. Each arm contained a photocell assembly located $12.5 \mathrm{~cm}$ from the beginning of the arm. Each assembly consisted of three photocells 
spaced $3 \mathrm{~cm}$ apart on an axis perpendicular to the grid floor. A response was recorded when any two of the three photobeams were interrupted simultaneously. Scrambled shock was delivered to the grid floor from a single shock source modeled after the GrasonStadler (Series 700) shock generator. The grids were $0.6 \mathrm{~cm}$ in diameter and spaced $1.5 \mathrm{~cm}$ apart center to center. The maze was housed in a dark, quiet room. Experimental events were programmed and data were recorded by a Digital 11T03-L computer.

Procedure. The rats were assigned randomly to one of four groups of 8 rats each. The rats were placed in the restraining tubes and given $0,40,80$, or 120 inescapable tailshocks on a variable-time 60 -sec schedule (range: 20 to $220 \mathrm{sec}$ ). Shock intensity was $1.0 \mathrm{~mA}$ and shock duration was $5.0 \mathrm{sec}$ on each trial. Rats in the 40-, 80-, and 120-shock conditions were removed from the tubes and returned to their home cages once the appropriate number of shocks had been delivered. Rats in the $\mathbf{0}$-shock group were restrained in the tubes for the same amount of time as the 120-shock group.

All rats were given 100 choice-escape trials in the Y-maze $24 \mathrm{~h}$ later. They were given $5 \mathrm{~min}$ to explore the maze prior to training, and then trials were presented on a fixed-time 45-sec schedule. Each trial began with the delivery of a $1.0-\mathrm{mA}$ shock to the grids and the presentation of one of four visual events (i.e., the end wall in one of the three alleys was illuminated for the duration of the trial or the maze remained dark throughout the trial). These events bore no consistent relationship to the position of the animal or to correct or incorrect choices. The presentation sequence was predetermined in a quasi-random order, such that each irrelevant event occurred five times in each block of 20 choice trials.

A correct response was recorded when a rat entered the alley to the left of its position at the start of the trial. If the alley to the right was chosen, an error was recorded, and choice of the alley to the left of the rat's new location was required to terminate shock. Following a correct response, shock and the visual cue terminated after a variable delay. Delay intervals of $200,350,450$, or $500 \mathrm{msec}$ were assigned randomly with replacement to each trial by the computer.

\section{Results and Discussion}

The mean percentage of trials with one or more errors and the mean latency to the first choice response are presented in blocks of 20 trials for each group in Figure 1. Error data are shown in the upper panel of the figure. All groups were as likely to choose the correct left alley as the incorrect right alley at the beginning of training. Thereafter, choice accuracy improved differentially among groups. Groups receiving 80 or 120 inescapable shocks 24 h earlier showed substantial impairment, with a slightly greater deficit occurring in the 120-shock condition. Rats in the 40-shock group performed as well as restrained controls ( 0 -shock group).

A mixed-design analysis of variance (ANOVA) on error data yielded significant main effects of group $[F(3,28)$ $=4.56, p<.02]$ and trial block $[F(4,112)=21.18$, $p<.001]$ and a marginally significant group $\times$ trial block interaction $[F(12,112)=1.78, p<.06]$. A comparison of overall mean percent errors in each group (Newman-Keuls $\alpha=.05$ ) indicated that the 80 - and 120 shock groups did not differ significantly from one another; however, both groups made significantly more errors than did the 40- and 0 -shock groups. Overall error rates did

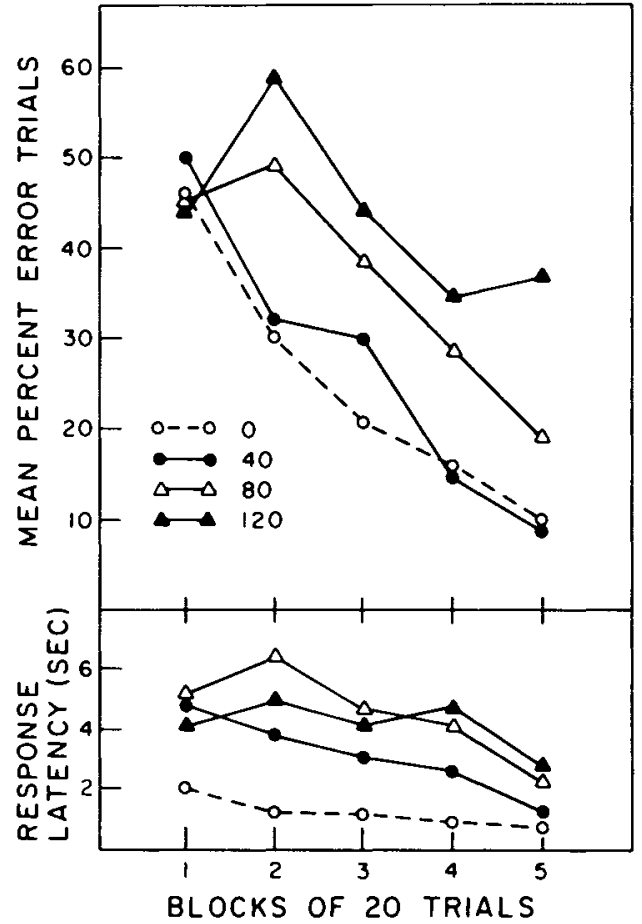

Figure 1. Mean percent error trials (upper panel) and mean latency to the first choice response (lower panel) in each hlocks of 20 trials for all groups in Experiment 2. The groups were exposed $100,40,80$, or 120 inescapable tailshocks 24 h prior to choice-escape testing. Irrelevant light cues were presented and shock terminated after a variable delay following correct choices in all groups.

not differ significantly between the 0 - and 40 -shock groups.

Latencies to the first choice response are presented in the lower panel of Figure 1. Elevated response latencies occurred for all preshocked groups. A mixed-design ANOVA yielded significant main effects of group $[F(3,28)=3.40, p<.03]$ and trial block $[F(4,112)=$ $5.02, p<.002$ ]; there was no significant interaction between variables. Newman-Keuls comparisons indicated that response latencies were significantly faster in the 0 shock group than in all other groups, which did not differ from one another.

These data indicate that magnitude of the choiceaccuracy deficit is affected by the severity of the pretreatment session. Preexposure to a minimum of 80 inescapable shocks was necessary to impair later choice-escape performance. A somewhat larger, though not significant, deficit in choice accuracy was observed following 120 inescapable shocks.

This experiment also provides additional evidence for the independence of response speed and choice accuracy (also see Jackson et al., 1980; Minor et al., 1984). Although preexposure to $\mathbf{4 0}$ inescapable shocks did not impair choice accuracy, it did elevate latencies to the first 
choice response. Longer latencies to initiate choices could reflect reduced motivation to engage in the instrumental response (Maier \& Seligman, 1976), competition from behavior strengthened during pretreatment (Bracewell \& Black, 1974; Glazer \& Weiss, 1976), or stress-induced motoric depression (Weiss et al., 1976).

\section{EXPERIMENT 2}

Although NE depletion following inescapable shock has been reported by several investigators, it was unclear at the time of this experiment whether the shock parameters typically used in our laboratories produced such an effect. Previous work on stress-induced catecholamine depletion in the helplessness paradigm had used shock parameters that were considerably more severe than are ours (e.g., Weiss et al., 1981) or had examined a species other than the rat (e.g., Anisman \& Sklar, 1979). Therefore, we sought to determine, in Experiment 2, whether NE depletion was a consequence of our pretreatment shock procedure and, more specifically, whether NE depletion at the time of testing could account for the pattern of choice performance obtained in each shock condition of the previous experiment.

The available data suggest that $\mathrm{NE}$ concentrations are depleted in the terminals of the ADTB immediately after exposure to inescapable shock (Weiss et al., 1981). These levels recover within $24 \mathrm{~h}$, but, with subsequent stresses, remain labile for 24 to $72 \mathrm{~h}$. For instance, Anisman and Sklar (1979) demonstrated that exposure to a few brief reinstating shocks $24 \mathrm{~h}$ after pretreatment with inescapable shock resulted in rapid utilization and depletion of hypothalamic NE in mice.

Reinstating shocks should mimic the effects of shock reexposure during the initial trials of choice testing. If this is so, the results of the Anisman and Sklar (1979) study suggest that significant NE depletion should occur early in training, at least following pretreatment with severe shock parameters. If the deficits in choice accuracy observed in Experiment 1 were related to depletion of forebrain NE, then the magnitude of the depletion produced by reinstating shocks should be a direct function of the severity of the pretreatment session. Specifically, reinstating shocks should be ineffective in depleting NE following pretreatment with 40 inescapable shocks; however, increasingly greater depletion should occur following 80 and 120 inescapable shocks.

In Experiment 2, rats were exposed to $0,40,80$, or 120 inescapable tailshocks and reexposed to 5 brief reinstating shocks $24 \mathrm{~h}$ later. Immediately after reinstatement, monoamine concentrations (NE, dopamine [DA], and serotonin [5-HT]) were assessed in two projection regions of the ADTB (i.e., hippocampus and remaining telencephalon). Monoamines also were assessed in groups exposed to either 0 or 120 shocks during pretreatment but not reexposed to shock $24 \mathrm{~h}$ later. These groups provided a measure of the level of NE recovery over the $24 \mathrm{~h}$ fol- lowing pretreatment in the least severe and most severe shock conditions.

\section{Method}

Subjects and Apparatus. Forty-eight male albino rats, weighing 290-327 g, were housed as in Experiment 1. The apparatus was the same as in Experiment 1.

Procedure. The rats were assigned randomly to one of four pretreatment conditions and were exposed to $0(n=16), 40(n=8)$, $80(n=8)$, or $120(n=16)$ inescapable tailshocks, as in Experiment 1.

Eight rats from each pretreatment condition were exposed to reinstating shocks in the $\mathrm{Y}$-maze $24 \mathrm{~h}$ later. Reinstatement began with a 5-min habituation period during which no shocks were presented. All rats then received five 5.0-sec, 1.0-mA inescapable grid shocks on a fixed-time 45-sec schedule (Groups 0-R, 40-R, 80-R, and 120$R)$. The rats were removed from the $Y$-maze $10 \mathrm{~min}$ after the last reinstating shock and immediately sacrificed via decapitation. The remaining rats in the 0 and 120 preshock conditions were not exposed to reinstating shocks (Groups 0-NR and 120-NR), but simply were removed from their home cages $24 \mathrm{~h}$ after pretreatment and sacrificed immediately. Brains were dissected on ice into hippocampus and remaining telencephalon, which were weighed and stored at $-80^{\circ} \mathrm{C}$ for no more than 2 weeks prior to neurochemical assays. Monoamine concentrations (NE, DA, and 5-HT) were assessed fluorometrically using the procedure of Jacobwitz and Richardson (1978).

\section{Results and Discussion}

Mean monoamine concentrations in the hippocampus and remaining telencephalon are given in Table 1 for each group. DA and 5-HT were not significantly affected by exposure to inescapable shock or reexposure to reinstating shocks $24 \mathrm{~h}$ later $[F \mathrm{~s}<1.33, p \mathrm{~s}>.05]$.

$\mathrm{NE}$ concentrations in each group are shown as a percentage of no-shock control levels (Group 0-NR) in Figure 2. Telencephalon NE (left panel) in Group 120NR was equivalent to control levels, indicating that any depletion resulting from immediate exposure to 120 inescapable shocks recovered within $24 \mathrm{~h}$. Reexposure to shock on Day 2 did not affect NE in Groups 0$\mathrm{R}$ and $40-\mathrm{R}$, but produced $23 \%$ and $34 \%$ reductions, respectively, in Groups $80-\mathrm{R}$ and $120-\mathrm{R}$. A single-factor ANOVA yielded a significant main effect of group $[F(5,42)=9.75, p<.0001]$. Planned comparisons indicated that telencephalon $\mathrm{NE}$ was equivalent in Groups 80-R and 120-R; however, both groups had significantly lower concentrations than did no-shock controls. Groups 0-NR, 120-NR, 0-R, and 40-R did not differ significantly from one another.

Exposure to 120 inescapable shocks (Group 120-NR) resulted, $24 \mathrm{~h}$ later, in levels of hippocampal NE (right panel of Figure 2) that were slightly higher than those of Group 0-NR. Reinstating shocks were effective in depleting hippocampal NE only in Group 120-R, which showed a $24 \%$ decrease relative to Group $0-\mathrm{NR}$ and a $45 \%$ decrease relative to Group 120-NR. A single-factor ANOVA revealed a significant main effect of group $[F(5,42)=8.02, p<.001]$. Planned comparisons indicated that the difference in NE concentrations between Groups 0-NR and 120-NR did not attain conventional 
Table 1

Mean and Standard Errors of the Mean Monoamine Concentrations (ng/g) in the Hippocampus and Remaining Telencephalon for All Groups in Experiment 2

\begin{tabular}{|c|c|c|c|c|c|c|c|c|c|c|c|c|}
\hline \multirow{3}{*}{$\begin{array}{c}\text { Monoamine } \\
\text { Concentration }\end{array}$} & \multicolumn{12}{|c|}{ Groups } \\
\hline & \multicolumn{2}{|c|}{ 0-NR } & \multicolumn{2}{|c|}{$120-N R$} & \multicolumn{2}{|c|}{$\mathbf{0}-\mathbf{R}$} & \multicolumn{2}{|c|}{$40-R$} & \multicolumn{2}{|c|}{$80-R$} & \multicolumn{2}{|c|}{$120-R$} \\
\hline & $M$ & $S E M$ & $M$ & $S E M$ & $M$ & $S E M$ & $M$ & $S E M$ & $M$ & $S E M$ & $M$ & $S E M$ \\
\hline \multicolumn{13}{|c|}{ Telencephalon } \\
\hline $\begin{array}{l}\text { Norepinephrine } \\
\text { Dopamine } \\
\text { Serotonin }\end{array}$ & $\begin{array}{r}382.6 \\
1540.9 \\
693.0\end{array}$ & $\begin{array}{l}18.1 \\
81.2 \\
45.6\end{array}$ & $\begin{array}{r}352.8 \\
1441.4 \\
717.8\end{array}$ & $\begin{array}{r}24.7 \\
110.6 \\
38.8\end{array}$ & $\begin{array}{r}371.7 \\
1513.3 \\
727.4\end{array}$ & $\begin{array}{r}12.3 \\
108.1 \\
67.9\end{array}$ & $\begin{array}{r}373.1 \\
1560.4 \\
738.9\end{array}$ & $\begin{array}{l}16.3 \\
77.8 \\
57.6\end{array}$ & $\begin{array}{c}292.7^{*} \\
1586.3 \\
687.3\end{array}$ & $\begin{array}{r}21.9 \\
104.5 \\
66.9\end{array}$ & $\begin{array}{c}249.9 * \\
1452.0 \\
704.3\end{array}$ & $\begin{array}{l}12.6 \\
99.2 \\
38.2\end{array}$ \\
\hline \multicolumn{13}{|c|}{ Hippocampus } \\
\hline $\begin{array}{l}\text { Norepinephrine } \\
\text { Serotonin }\end{array}$ & $\begin{array}{l}432.6 \\
532.7\end{array}$ & $\begin{array}{l}23.2 \\
33.6\end{array}$ & $\begin{array}{l}519.3 \dagger \\
581.5\end{array}$ & $\begin{array}{l}37.0 \\
53.9\end{array}$ & $\begin{array}{l}430.4 \\
518.0\end{array}$ & $\begin{array}{l}24.0 \\
56.7\end{array}$ & $\begin{array}{l}463.0 \\
547.3\end{array}$ & $\begin{array}{l}28.6 \\
48.9\end{array}$ & $\begin{array}{l}458.1 \\
516.4\end{array}$ & $\begin{array}{l}37.1 \\
24.8\end{array}$ & $\begin{array}{l}327.9 * \ddagger \\
567.0\end{array}$ & $\begin{array}{l}28.0 \\
35.6\end{array}$ \\
\hline
\end{tabular}

*Significantly different from Group 0 -NR by at least $p<.05$. †Marginally different from Group 0-NR $(p<.07)$. $\quad$ Significantly different from Group 120-NR $(p<.001)$.

levels of significance $(p<.07)$. Norepinephrine did not differ significantly among Groups $0-\mathrm{NR}, 0-\mathrm{R}, 40-\mathrm{R}$, and 80-R. However, hippocampal NE was significantly lower in Group 120-R than in Groups 0-NR and 120-NR.

These data suggest that, within $24 \mathrm{~h}, \mathrm{NE}$ in the terminals of the ADTB had recovered from the immediate effects of inescapable shock. Although recovery was not charted for all preshock conditions, Group 120-NR had NE levels equal to or higher than those of nonstressed controls (Group 0-NR) at the time of reinstatement. Thus, complete recovery probably occurred when fewer inescapable shocks were presented during pretreatment.

The impact of reinstating shocks was strongly influenced by the severity of the pretreatment session. Reinstating shocks by themselves were not sufficient to deplete $\mathrm{NE}$, as demonstrated by the fact that NE levels in Groups $0-R$ and $40-R$ were equivalent to those of no-shock controls. The effect of reinstatement was clearly augmented by prior exposure to 80 or 120 inescapable shocks. Telencephalic NE was significantly reduced in both of these preshock conditions, with a slightly greater depletion in Group 120-R. Hippocampal NE was significantly depleted in Group 120-R but not in Group 80-R. Because preexposure to 80 inescapable shocks was effective in disrupting choice performance in Experiment 1, the absence of a significant depletion in Group 80-R may indicate that hippocampal NE is not a crucial determinant of choice performance. However, NE concentrations were assessed after only five shock trials in the present study. Significant depletion of hippocampal NE might have occurred in Group 80-R if more reinstating shocks had been given. Because 30 to 40 trials are required before control subjects show a significant reduction in errors in the choice task, a contribution of the hippocampus to choice perfor-

TELENCEPHALON HIPPOCAMPUS

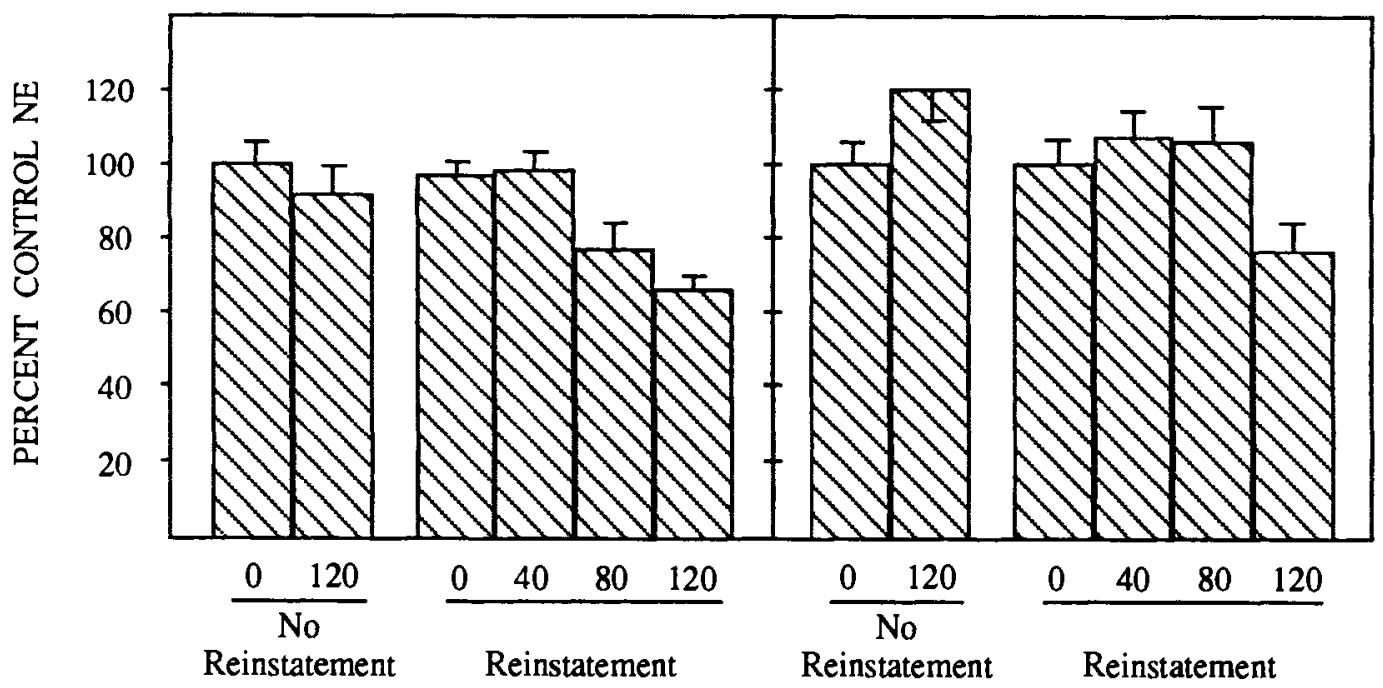

Figure 2. Mean norepinephrine concentrations $( \pm S E M)$ in the hippocampus and remaining telencephalon for all groups in Experiment 1 . The rats were exposed to $0,40,80$, or 120 inescapable tailshocks. Twenty-four hours later, rats from each preshock condition were exposed to five brief reinstating shocks (Groups 0-R, 40-R, 80-R, and 120R). Groups O-NR and 120-NR were not reexposed to shock. 
mance should not be dismissed without additional information.

Depletion of telencephalic NE was somewhat greater in the present study than in previously reported studies (e.g., Anisman \& Zacharko, 1986; Weiss et al., 1981; Weiss \& Simson, 1985). At least two aspects of the present procedure may have contributed to this outcome. Relatively mild stressors typically have been used to reinstate the effects of preexposure to inescapable shock (e.g., Anisman \& Sklar, 1979; Weiss et al., 1981). By contrast, rats in the present study were exposed to relatively intense, $1.0-\mathrm{mA}$ reinstating shocks in an attempt to mimic the effects of the first few trials of choice testing in Experiment 1 . If more intense shocks result in higher levels of activity in noradrenergic neurons, greater depletion would be expected under the present reinstatement procedure.

Conditioning also may have contributed to the level of NE depletion in the present study. Cassens, Roffman, Kuruc, Ursulak, and Schildkraut (1980) reported that reexposure to the chamber in which rats had received inescapable shocks $24 \mathrm{~h}$ earlier resulted in rapid utilization of NE, suggesting that activity in noradrenergic neurons can be conditioned. Although the rats of the present study were not returned to the original pretreatment context, strongly conditioned contextual cues were present during reinstatement. Minor and LoLordo (1984) demonstrated that the adverse effects of inescapable shock generalize from pretreatment to the test situation along an odor dimension in rats. The stress-produced odorants of shocked conspecifics accumulate in an aversive conditioning apparatus that is not cleaned frequently. These odors become strongly associated with inescapable shock during pretreatment. Similar odorants in the test chamber serve to mediate the associative effects of inescapable shock across physically different environments. The presence of such odor cues during reinstatement may have resulted in conditioned enhancement of noradrenergic activity, as in the Cassens et al. study, thereby facilitating depletion of telencephalic NE.

Overall, these data are consistent with the idea that the disruptive effect of irrelevant cues on choice performance in Experiment 1 resulted from stress-induced depletion of NE by inescapable shock. Manipulating the number of inescapable preshocks had the same ordinal effect on depletion of forebrain NE and magnitude of the choice accuracy deficit. A few reinstating shocks rapidly depleted NE following pretreatment with 80 or 120 , but not with 40 , inescapable shocks. This outcome suggests that the first few choice trials in Experiment 1 were sufficient to alter NE transmission in the 80- and 120-preshock groups, well before the task was learned. Assuming that the ability to shift attention from irrelevant cues decreased with decreases in NE levels, the overall difficulty of the choice task should have increased for these groups, and acquisition should, accordingly, have been impaired.

Unfortunately, these data cannot be taken as compelling evidence that NE depletion is responsible for choiceaccuracy deficits for several reasons. Most importantly, the adverse effects of inescapable shock are not limited to noradrenergic neurons. Concomitant alteration of cholinergic (Anisman, 1975), serotinergic (Hellhammer, Bell, Ludwig, \& Rea, 1983), dopaminergic (Anisman \& Zacharko, 1986), GABAergic (Petty \& Sherman, 1981), and opioidergic neurotransmission (Maier, 1986) has been indicated by data or implicated by theory. The apparent relationship between severity of pretreatment session, level of NE depletion, and magnitude of choice-accuracy deficit may simply mirror the general level of neural imbalance produced by inescapable shock. Any neurotransmitter might show similar concordance with behavioral data if measured appropriately. Experiments 1 and 2 do not rule out the possibility that alteration of some other neurotransmitter or combination of transmitters mediates the choice-accuracy deficit. Experiment 3 provided a more direct assessment of the role of NE depletion in the choice task.

\section{EXPERIMENT 3}

In this experiment, our aim was to determine whether depletion of forebrain NE would be sufficient to impair choice performance. Forebrain NE was depleted via bilateral, 6-OHDA lesions of the ADTB. Chemical lesions provided a more direct assessment of the role of $\mathrm{NE}$ depletion in the choice-accuracy deficit by eliminating the potentially extraneous neurochemical changes produced by inescapable shock.

Chemical lesions of the ADTB should mimic the effects of inescapable shock on later choice performance if NE depletion is a critical determinant. Lesioned rats should show a deficit in choice accuracy only when salient, task-irrelevant stimuli are presented during choice trials. In the absence of such cues, lesioned rats should perform as well as vehicle controls. Moreover, the magnitude of any impairment following chemical depletion should be comparatively larger than that observed in Experiment 2. Experiments 1 and 2 suggest that the magnitude of the choice-accuracy deficit increases with the level of forebrain NE depletion. Chemical lesions virtually eliminate forebrain NE; hence, shifting attention away from salient task-irrelevant stimuli should be exceedingly difficult, resulting in an unusually large deficit in choice accuracy.

Rats initially received bilateral infusion of 6-OHDA or vehicle into the ADTB. Equal numbers of rats from each surgery condition received choice-escape training either in the presence of or in the absence of irrelevant intramaze cues. Task difficulty was increased in all groups by variably delaying shock termination after correct choices.

\section{Method}

Subjects and Apparatus. Thirty-two male albino rats, weighing 290-320 g, were obtained from Charles River Company and housed as in Experiment 1. The apparatus was the same as in Experiment 1.

Procedure. The rats were unsystematically assigned to one of two surgery conditions of 16 rats each. In the lesion (DB) condition, rats received bilateral infusion of $4 \mu \mathrm{g}$ (free base) 6$\mathrm{OHDA} \cdot \mathrm{HBr}$ (Regis Chemical). The 6-OHDA was dissolved at a 
concentration of $10 \mu \mathrm{g} / \mu \mathrm{l}$ in a vehicle of $0.9 \%$ saline and $0.02 \%$ ascorbic acid. Toxin was infused at a rate of $0.2 \mu \mathrm{l} / \mathrm{min}$ through a 30-ga stainless steel cannula, which was stereotaxically placed $1.3 \mathrm{~mm}$ anterior to ear-bar zero, $\pm 1.1 \mathrm{~mm}$ lateral to the sagittal suture, and $6.4 \mathrm{~mm}$ ventral to the surface of the skull. In the control (C) condition, rats underwent identical surgery, except that saline vehicle rather than toxin was infused. The rats were allowed 7 to 10 days to recover from surgery

All rats then received 120 choice-escape trials in the $\mathrm{Y}$-maze. Equal numbers of rats from each surgery condition were assigned randomly to one of two test conditions. Two groups (DB-IC and C-IC) were trained in the presence of irrelevant, intramaze light cues, as in Experiment 1. No irrelevant cues were presented to the other two groups (DB-NIC and C-NIC): All three maze arms were illuminated simultaneously at the start of each trial. As in Experiment 1 , the variable delay of shock termination following correct choice responses was in effect for all groups.

Four rats from each group were chosen at random and sacrificed via decapitation 5-7 days after choice-escape testing. Brains were dissected on ice into hippocampus and remaining telencephalon. Brain tissue was stored at $-80^{\circ} \mathrm{C}$ for no more than 2 weeks before monoamine concentrations were assayed (Jacobwitz \& Richardson, 1978) to determine the effectiveness of dorsal bundle lesions.

\section{Results and Discussion}

The results of choice-escape training in each group are shown in Figure 3. The percentage of trials with one or more errors in each block of 20 trials is presented in the upper panel of the figure. Lesions of the ADTB produced only slight impairment of choice acquisition (Group DB$\mathrm{NIC}$ ), relative to vehicle controls (Group C-NIC), when intramaze cues were not presented. By contrast, the presence of irrelevant stimuli dramatically disrupted choice performance in lesioned (Group DB-IC) but not

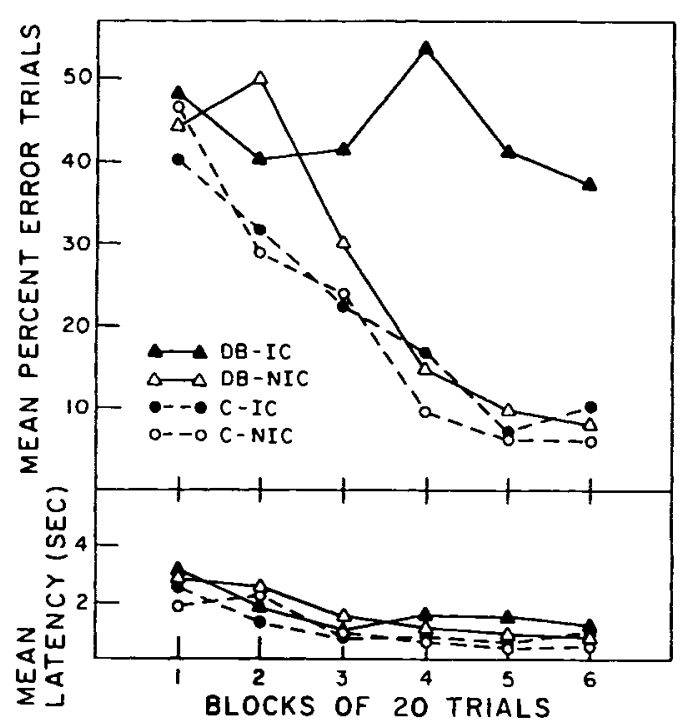

Figure 3. Mean percent error trials (upper panel) and mean latencies to the first choice response (lower panel) for each block of 20 trials for all groups in Experiment 3. Lesioned (DB) and vehicle control (C) rats received choice-escape training either in the presence of (Groups DB-IC and C-IC) or the absence of (Groups DB-NIC and C-NiC) an irrelevant light cue. Shock terminated after a variable delay following correct choices in all groups.
Table 2

Mean and Standard Error of the Mean Monoamine Concentrations (ng/g) in the Hippocampus and Remaining Telencephalon for Dorsal Bundle Lesion and Vehicle Control Rats in Experiment 3

\begin{tabular}{|c|c|c|c|c|}
\hline \multirow{3}{*}{$\begin{array}{c}\text { Monoamine } \\
\text { Concentration }\end{array}$} & \multicolumn{4}{|c|}{ Groups } \\
\hline & \multicolumn{2}{|c|}{ Lesion } & \multicolumn{2}{|c|}{ Control } \\
\hline & $M$ & $\overline{S E M}$ & $M$ & $\overline{S E M}$ \\
\hline \multicolumn{5}{|c|}{ Telencephalon } \\
\hline Norepinephrine & $151.6^{*}$ & 12.6 & 412.0 & 24.7 \\
\hline Dopamine & 1542.1 & 74.3 & 1657.8 & 89.0 \\
\hline Serotonin & 688.5 & 40.3 & 714.5 & 48.9 \\
\hline \multicolumn{5}{|c|}{ Hippocampus } \\
\hline Norepinephrine & $77.4^{*}$ & 7.6 & 516.9 & 20.3 \\
\hline Serotonin & 549.9 & 23.4 & 589.2 & 38.8 \\
\hline
\end{tabular}

*Significantly different from vehicle control group $(p s<.0001)$.

in control rats (Group C-IC). Group DB-IC essentially failed to improve choice accuracy over 120 trials of training.

A mixed-design ANOVA on error data yielded main effects of group $[F(3,28)=19.75, p<.0001]$ and trial block $[F(5,140)=36.92, p<.0001]$ and a significant group $\times$ trial block interaction $[F(15,140)=4.01$, $p<.0001]$. A comparison of overall error rates among groups (Newman-Keuls $\alpha=.05$ ) indicated that Group DB-IC made significantly more errors over the course of training than did all other groups, which did not differ from one another. A single-factor ANOVA was computed for errors in the second block of 20 trials to determine whether Group DB-NIC showed significantly retarded choice accuracy early in training. A significant effect of group $[F(3,28)=3.81, p<.03]$ and subsequent post hoc contrasts indicated that Group DB-NIC did not differ from Group DB-IC, but made significantly more errors than did either control group.

As shown in the lower panel of Figure 3, latencies to the first-choice response were not influenced by ADTB lesions or the presence of irrelevant cues. All groups were equally fast to respond. A mixed-design ANOVA (group $X$ trial block) yielded a significant main effect of trial block $[F(5,140)=9.45, p<.0001]$, indicating that latencies decreased across trials. No other main effects or interactions were statistically significant.

Table 2 shows monoamine concentrations in the hippocampus and remaining telencephalon for the sample of lesioned and vehicle rats. Lesions of the ADTB resulted in significant $63 \%$ and $85 \%$ reductions in telencephalic and hippocampal $\mathrm{NE}$, respectively $[t \mathrm{~s}(14)>9.36$, ps $<.0001]$ relative to control levels. There were no significant or suggestive differences between cue and no-cue conditions in NE levels, regardless of surgery condition. DA and 5-HT were not affected by lesions.

The present data indicate that bilateral 6-OHDA lesions of the ADTB are sufficient to impair choice-escape performance. Substantial deficits in choice accuracy were observed among lesioned rats only when irrelevant visual 
cues were presented on each choice trial. In the absence of such cues, lesioned rats showed only transient impairment relative to saline controls. Thus, 6-OHDA lesions generally disrupted performance in much the same way as inescapable shock (cf. Minor et al., 1984). These data are consistent with the hypothesis that NE depletion is importantly related to the deficit in choice accuracy resulting from preexposure to inescapable shock. Note, however, that some cautionary notes on this conclusion are raised below.

This experiment also provides evidence for the independence of deficits in response speed and choice accuracy. Even though ADTB lesions produced a large deficit in choice accuracy, response speed was no different from that of control subjects. A role for NE in decreased motor performance is, however, not eliminated by the present data. As discussed later, Weiss and Simson (1985) argued that decreased motor activity in rats results from a stressenhanced noradrenergic input to the forebrain. The large depletion of forebrain NE via ADTB lesions may have precluded such an increase, thereby eliminating deficits in response speed and motor performance.

\section{GENERAL DISCUSSION}

This investigation provides initial evidence that the disruptive effect of irrelevant cues on choice performance in inescapably shocked rats is related to the depletion of forebrain NE. In Experiments 1 and 2, the severity of the pretreatment session was varied by exposing rats to different numbers of inescapable shocks. This manipulation had similar effects on the magnitude of the choice-accuracy deficit (Experiment 1) and on depletion of NE upon reexposure to shock (Experiment 2). While 40 inescapable shocks failed to impair choice performance or deplete NE, preexposure to 80 or 120 inescapable shocks resulted in deficits by both measures, with somewhat greater impairment associated with the larger number of shocks. Experiment 3 demonstrated that 6-OHDA lesions of the ADTB, which produced substantial depletion of forebrain $\mathrm{NE}$, were sufficient to impair choice-escape performance. Such lesions affected choice performance in much the same way as inescapable shock (cf. Minor et al., 1984). Choice accuracy was impaired only when task-irrelevant cues were presented on choice trials. In the absence of such cues, lesioned rats performed as well as saline controls.

Weiss et al. (1981) argued that stress-induced depletion of NE occurs when the rate of NE utilization exceeds the rate of synthesis. From this view, noradrenergic neurons of the ADTB probably undergo a period of exaggerated activity, followed by a period of relative quiescence, when inescapably shocked rats are reexposed to shock $24 \mathrm{~h}$ after the initial stress session. The results of Experiment 2 indicated that hippocampal and telencephalic NE recovered to normal levels within $24 \mathrm{~h}$ of the pretreatment session. These levels were rapidly depleted when the most severe pretreatment conditions were followed after $24 \mathrm{~h}$ by a few reinstating shocks, suggesting a high rate of NE utilization in these brain regions early in testing (also see Anisman \& Sklar, 1979; Cassens et al., 1980). As NE concentrations are progressively depleted, however, noradrenergic input to the forebrain should decrease, perhaps resulting in a functional lesion.

Whether it is increased or decreased noradrenergic activity that is more central to the deleterious effects of inescapable shock remains at issue. The answer to this question, however, may depend upon the type and severity of test task used to assess helplessness. Helplessness is not a unitary phenomenon; rather, it appears to be two or more clusters of disorders that share a common etiology. Test tasks that assess different aspects of helplessness have been identified (see Maier \& Jackson, 1979, for a discussion), and these may have different neuroanatomical concomitants. It is also possible that some tasks are more sensitive to increased release of forebrain NE, whereas others reflect a decrease.

Weiss and Simson (1985) provided convincing evidence that an increase in noradrenergic activity in the ADTB contributes to diminished motor activity in a swim task in rats exposed to inescapable shock $24 \mathrm{~h}$ earlier. Increased noradrenergic output was traced to a relatively long-lasting NE depletion in the locus coeruleus, resulting in disinhibition of ADTB neurons. In this task, the amount of time spent floating was negatively correlated with NE concentrations in the locus coeruleus. Such behavioral depression was reversed by increasing NE synthesis or transmission in this region, or by stimulating $\alpha_{2}$ receptors with pharmacological agonists. These data suggested that stress-induced NE depletion in the locus coeruleus represented a functional blockade of autoreceptors, which normally inhibit NE release in the terminals of the ADTB. Evidence that behavioral depression was related to an increase in forebrain NE was provided by intracerebral infusion of $\alpha_{1}$ and $\beta$ adrenergic receptor agonists, which mimicked the effect of inescapable shock on floating time.

Although enhanced noradrenergic input to the forebrain may contribute to the longer response latencies of inescapably shocked rats during choice testing, it is less likely to account for deficits in choice accuracy. Most importantly, lesions of the ADTB produced the same type of choice-accuracy deficit that was observed in inescapably shocked rats in previous work (Minor et al., 1984). Although NE was not entirely eliminated by this manipulation, NE concentrations in lesioned rats were substantially below control levels, suggesting that the choiceaccuracy deficit resulted from reduced noradrenergic input to the forebrain.

Moreover, any initial stress-induced increase in noradrenergic activity in Experiments 1 and 2 may have been too short to have a long-lasting influence on performance. Reexposure to intense electric shocks during choice testing probably was more stressful than was the placement in tepid water used in Weiss and Simson's (1985) studies. If stressfulness of the test paradigm in- 
fluences the rate of NE utilization, faster NE utilization and depletion would have been expected in the present study. Indeed, under the most severe pretreatment conditions, only five reinstating shocks were required to significantly deplete NE in Experiment 2. Presumably, such depletion was accompanied by decreased NE input to the forebrain. Because $\mathbf{3 0}$ to $\mathbf{4 0}$ trials are required before control rats show a significant elimination of errors in the choice task, the reduction in forebrain NE probably occurred well before the correct contingencies were learned.

Nonetheless, additional information is needed before we can come to any strong conclusions regarding the role of NE depletion in the choice-accuracy deficit. Because 6-OHDA lesions produced greater depletion of NE than did preexposure to inescapable shock, the relevance of the two manipulations to each other can be questioned. Even though preexposure to a large number of inescapable shocks produced rapid depletion of NE during reinstatement in Experiment 2, it is unclear whether such a decrease reflected a concomitant change in the functional capacity of noradrenergic neurons. Such neurons may have been capable of releasing large quantities of $\mathrm{NE}$ throughout training, despite a statistically significant reduction in neurotransmitter concentration. Addressing this issue requires more precise knowledge of the status of NE neurons throughout choice training. In this regard, the analysis of choice performance would benefit from the type of pharmacological manipulations used by Weiss and Simson (1985). Stimulation and blockade of forebrain $\alpha_{1}$ and $\beta$ receptors should have exactly opposite effects on motor performance and choice accuracy if the above analysis is correct. For instance, although intracerebral infusion of receptor agonists mimicked the effects of inescapable shock on motor performance (Weiss \& Simson, 1985), these agents should not affect choice accuracy. Conversely, blockade of $\alpha_{1}$ and $\beta$ receptors should mimic the effects of inescapable shock on choice accuracy but should leave motor performance unaffected.

\section{Anxiety, Helplessness, and Attention}

Minor et al. (1984) interpreted the finding that inescapably shocked rats are more readily disrupted by irrelevant cues in the choice task within a general anxiety framework and the Yerkes-Dodson law. Yerkes and Dodson (1908) had argued that there was an optimal level of arousal or anxiety for discriminative performance, which decreased as task difficulty increased, and that thus both overarousal and underarousal were detrimental to performance. More recent interpretations of this law suggest that overanxious subjects perform poorly in cognitive tasks because they have difficulty filtering out irrelevant information and attending to the task at hand (Easterbrook, 1959; Hamilton, Hockey, \& Rejman, 1977; Walley \& Weiden, 1973, 1974).

There is growing evidence that inescapably shocked rats enter the test phase of the helplessness experiment in a more anxious state than do escapably shocked and restrained controls. Minor and LoLordo (1984) demon- strated that the deleterious effects of inescapable shock generalize to later escape tasks along an odor dimension in rats. Odors and other contextual cues that have been paired with inescapable shock have been found to be more fear-inducing than are cues associated with escapable shock or simple restraint (Mineka, Cook, \& Miller, 1984; Minor, 1988). Because similar odorants were likely to have been present in the pretreatment and Y-maze in the present study (see Minor \& LoLordo, 1984, for a discussion), the level of anxiety at the beginning of training should have been higher for inescapably shocked rats than for control animals. From this view, the finding that inescapably shocked rats have difficulty ignoring salient irrelevant cues during choice testing is consistent with the earlier work on anxiety and attention.

Implication of the ADTB in the choice-accuracy deficit also is consistent with this anxiety interpretation. The phasic response of ADTB neurons, which is augmented by the presentation of aversive or novel stimuli (Jacobs, 1986), has been hypothesized to play a central role in anxiety (Gray, 1982; Redmond, 1979; Redmond \& Huang, 1979). In this regard, Jackson and Minor (1988) suggested that the differential effects of escapable and inescapable shock may stem from the temporal and intensity characteristics of the anxiety response elicited by each event. While exposure to inescapable shock may result in a chronic state of anxiety during the pretreatment session, escapable shock may produce moderate levels of acute fear. On a more molecular level, this behavioral description may translate into chronic activation of the ADTB during pretreatment with inescapable shock, resulting in depletion of NE concentrations in the locus coeruleus and terminals, thus rendering the tract susceptible to later stresses.

Finally, several lines of evidence suggest that an alteration of forebrain NE should influence sensory processing. The disruptive effect of irrelevant cues on the choice performance of inescapably shocked rats is logically similar to the disruption of performance following lesions of the ADTB in paradigms such as blocking (Lorden, Rickert, Dawson, \& Pelleymounter, 1980), unblocking and superconditioning (Rickert \& Lorden, 1983), latent inhibition (Lorden, Rickert, \& Berry, 1983; Mason \& Fibiger, 1979), response-based appetitive choice in which spatial cues may have controlled performance (Archer, Mohammed, Ross, \& Soderberg, 1983), and appetitive choice in the presence of discrete irrelevant stimuli (Roberts, Price, \& Fibiger, 1976). All of these tasks require the subject to learn the irrelevance of (or the significance of) certain stimuli for accurate performance. Choice performance, however, is disrupted by irrelevant stimuli in inescapably shocked rats only when task difficulty is increased by delaying shock termination following correct choice responses (Minor et al., 1984). This outcome suggests that reduced forebrain NE does not unconditionally disrupt sensory or attentional processing. When the correct task contingencies are degraded or complex, subjects may perseverate on salient features of the 
environment or on prepared or well-learned response strategies (also see Anisman \& Zacharko, 1986).

\section{REFERENCES}

Anisman, H. (1975). Time dependent variations in aversively motivated behavior: Nonassociative effects of cholinergic and catecholaminergic activity. Psychological Review, 82, 359-385.

Anisman, H., \& SkLar, L. S. (1979). Catecholamine depletion in mice upon reexposure to stress: Mediation of the escape deficits produced by inescapable shock. Journal of Comparative \& Physiological Psychology, 98, 610-625.

ANISMAN, H., \& ZACHARKo, R. M. (1986). Behavioral and neurochemical consequences associated with stressors. Annals of the New York Academy of Sciences, 467, 205-225.

ARChER, T., Mohammed, A. K., Ross, S. B., \& Soderberg, U. (1983). T-maze learning, spontaneous activity and food intake recovery following systemic administration of the noradrenaline neurotoxin, DSP4. Pharmacology, Biochemistry \& Behavior, 19, 121-130.

Aston-Jones, G. (1985). Behavioral function of the locus coeruleus derived from cellular attributes. Physiological Psychology, 13, 118-126.

BraCeWELl, R. J., \& BLACK, A. H. (1974). The effects of restraint and noncontingent pre-shock on subsequent escape learning in the rat. Learning \& Motivation, 5, 53-69.

Cassens, G., Roffman, M., Kuruc, A., Ursulak, P. J., \& SchildKRAUT, J. J. (1980). Alterations of brain norepinephrine metabolism induced by environmental stimuli previously paired with inescapable shock. Science, 209, 1138-1140.

EAsterbrooK, J. A. (1959). The effects of emotion on cue utilization and the organization of behavior. Psychological Review, 66, 183-201.

Foote, S. L., Bloom, F. E., \& Aston-Jones, G. (1983). The nucleus locus coeruleus: New evidence of anatomical and physiological specificity. Physiology Review, 63, 844-914.

Glazer, H. I., \& WeISS, J. M. (1976). Long-term interference effect: An alternative to "learned helplessness." Joumal of Experimental Psychology: Animal Behavior Processes, 2, 201-213.

GraY, J. A. (1982). The neuropsychology of anxiety. Oxford: Oxford University Press.

Hamilton, P., Hockey, G. R., \& Rejman, M. (1977). The place of the concept of activation in human information processing: An integrative approach. In S. Dornic (Ed.), Attention and performance (Vol. 6, pp. 121-145). Hillsdale, NJ: Erlbaum.

Hellhammer, D. H., Bell, M., LudWig, M., \& ReA, M. A. (1983). Learned helplessness: Effects on brain monoamines. Society for Neuroscience Abstracts, 9, 555.

IRWIN, J., SUISSA, A., \& ANISMAN, H. (1980). Differential effects of inescapable shock on escape performance and discrimination learning in a water escape task. Joumal of Experimental Psychology: Animal Behavior Processes, 6, 21-42.

Jackson, R. L., AleXander, J. H., \& MaIer, S. F. (1980). Learned helplessness, inactivity, and associative deficits: Effects of inescapable shock on response choice escape learning. Journal of Experimental Psychology: Animal Behavior Processes, 6, 1-20.

JACKSON, R. L., \& MINOR, T. R. (1988). Effects of signaling inescapable shock on subsequent escape learning: Implications for theories of coping and learmed helplessness. "Manuscript submitted for publication.

JACOBS, B. L. (1986). Single unit activity of brain monoamine-containing neurons in freely moving animals. Annals of the New York Academy of Sciences, 473, 70-77.

JACOBWITZ, D. M., \& Richardson, J. (1978). Method for the rapid determination of norepinephrine, dopamine, and serotonin in the same brain region. Pharmacology, Biochemistry \& Behavior, 8, 515-519.

LOONEY, T. A., \& CoHEN, P. S. (1972). Retardation of a jump-up escape response in rats pretreated with different frequencies of shock. Journal of Comparative \& Physiological Psychology, 78, 317-322. LORDEN, J. F., RICKERT, E. J., \& BeRRY, D. W. (1983). Forebrain monoamines and associative learning: I. Latent inhibition and conditioned inhibition. Behavioral Brain Research, 9, 181-199.
Lorden, J. F., Rickert, E. J., Dawson, R., Pelleymounter, M. A. (1980). Forebrain norepinephrine and the selective processing of information. Brain Research, 190, 569-573.

MAIRR, S. F. (1986). Stressor controllability and stress-induced analgesia. Annals of the New York Academy of Sciences, 467, pp. 55-72.

Maier, S. F., Albin, R. W., \& Testa, T. J. (1973). Failure to learn to escape in rats previously exposed to inescapable shock depends on the nature of the escape response. Journal of Comparative \& Physiological Psychology, 85, 581-592.

MAIER, S. F., \& JACKson, R. L. (1979). Learned helplessness: All of us were right (and wrong): Inescapable shock has multiple effects. In G. H. Bower (Ed.), The psychology of learning and motivation (Vol. 13, pp. 155-218). New York: Academic Press.

Maier, S. F., \& Seligman, M. E. P. (1976). Learned helplessness: Theory and evidence. Journal of Experimental Psychology: General, 105, 3-46.

Maier, S. F., Sherman, J. E., LeWis, J. W., Terman, G. W., LieBESKIND, J. C. (1983). The opioid/nonopioid nature of stress-induced analgesia and learned helplessness. Journal of Experimental Psychology: Animal Behavior Processes, 9, 80-91.

MAsON, S. T. (1980). Noradrenaline and selective attention: A review of the model and the evidence. Life Sciences, 27, 617-631.

MAsON, S. T., Fibiger, H. C. (1979). Noradrenaline and selective attention. Life Sciences, 25, 1949-1956.

MineKA, S., CoOK, M., Miller, S. (1984). Fear conditioned with escapable and inescapable shock: Effects of a feedback stimulus. Journal of Experimental Psychology: Animal Behavior Processes, 10, 307-324.

MINOR, T. R. (1988). Conditioned fear and neophobia following inescapable shock. Manuscript in preparation.

MinOR, T. R., JACKSON, R. L., \& MAIER, S. F. (1984). Effects of taskirrelevant cues and reinforcement delay on choice escape learning following inescapable shock: Evidence for a deficit in selective attention. Joumal of Experimental Psychology: Animal Behavior Processes, 10, 543-556.

MinOR, T. R., \& LoLordo, V. M. (1984). Escape deficits following inescapable shock: The role of contextual odor. Journal of Experimental Psychology: Animal Behavior Processes, 10, 168-181.

PeTtY, F., \& Shrrman, A. D. (1981). GABAergic modulation of learned helplessness. Pharmacology, Biochemistry \& Behavior, 15, 567-570.

ReDmOND, D. E. (1979). New and old evidence for the involvement of a brain norepinephrine system in anxiety. In W. G. Fann, I. Karacan, A. D. Pokorny, \& R. L. Williams (Eds.), Phenomenology and treatment of anxiety (pp. 153-203). New York: Spectrum.

Redmond, D. E., \& HuANG, Y. H. (1979). New evidence for a locus coeruleus-norepinephrine connection with anxiety. Life Sciences, 25 , 2149-2162.

RICKERT, E. J., \& LORDEN, J. F. (1983). Forebrain monoamines and associative learning: II. Superconditioning/unblocking. Behavioral Brain Research, 9, 201-211.

Roberts, D. C. S., Price, M. T. C., \& Fibiger, H. C. (1976). The dorsal tegmental noradrenergic projection: An analysis of its role in maze learning. Journal of Comparative \& Physiological Psychology, 90, 363-372.

Rosellini, R. A., DeCola, J. P., \& Shapiro, N. R. (1982). Cross motivational effects of inescapable shock are associative in nature. Journal of Experimental Psychology: Animal Behavior Processes, 8, 376-388.

SEGAL, M. (1985). Mechanisms of action of noradrenaline in the brain. Physiological Psychology, 13, 172-178.

Seligman, M. E. P., Rosellini, R. A., \& Kozak, M. J. (1975). Learned helplessness in the rat: Time course, immunization and reversibility. Journal of Comparative \& Physiological Psychology, 88, 542-547.

WALLEY, R. E., \& WEIDEN, T. D. (1973). Latent inhibition and cognitive masking: A neuropsychological theory of attention. Psychological Review, 80, 540-542.

W Alley, R. E., \& Weiden, T. D. (1974). Giving flesh to a "straw man": A reply to Feeney, Pittman, and Wagner. Psychological Review, 81, 540-542.

Weiss, J. M., Glaser, H. I., \& Pohorecky, L. A. (1976). Coping 
behavior and neurochemical changes: An alternative explanation to the original "learned helplessness" experiments. In G. Serban \& A. Kling (Eds.), Animal models of human psychobiology (pp. 141174). New York: Plenum Press.

Weiss, J. M., Goodman, P. A., Losito, B. G., Corrigan, S., Charry, J. M., BAILEY, W. H. (1981). Behavioral depression produced by an uncontrollable stressor: Relationship to norepinephrine, dopamine, and serotonin levels in various regions of rat brain. Brain Research Reviews, 3, 167-205.

WeIss, J. M., \& Simson, P. G. (1985). Neurochemical mechanisms underlying stress-induced depression. In T. Field, P. McCabe, \&
N. Schneiderman (Eds.), Stress and coping (pp. 93-116). Hillsdale, NJ: Erlbaum.

Weiss, J. M., Stone, E. A., \& Harrell, N. (1970). Coping behavior and brain norepinephrine level in rats. Joumal of Compararive \& Physiological Psychology, 72, 153-160.

YeRKEs, R. M., DoDson, J. D. (1908). The relation of strength of a stimulus to rapidity of habit formation. Journal of Comparative Neurology \& Psychology, 18, 458-482.

(Manuscript received July 17, 1987;

revision accepted for publication February 22, 1988.) 